\section{Cryoglobulinemic vasculitis in the era of direct-acting antiviral drug}

We thank Moiseev et al for their interest in our work regarding sofosbuvir and ribavirin in hepatitis $\mathrm{C}$ virus (HCV)-associated mixed cryoglobulinemia vasculitis (VASCUVALDIC study) ${ }^{1}$ and to bring new elements for discussion.

Moiseev et al emphasise that treatment with immunomodulatory or immunosuppressive therapy (including rituximab) may have contributed to the impressive results of the VASCUVALDIC study. We have to stress that with the advent of new direct-acting antiviral (DAA) drugs (ie, sofosbuvir plus ribavirin), up to $87.5 \%$ of patients achieved complete clinical remission while only $17 \%$ of patients required the use of rituximab and glucocorticosteroids associated with antiviral therapy. ${ }^{1}$ In comparison, first-generation protease inhibitors (telaprevir or boceprevir) plus peginterferon and ribavirin allowed 70\% complete clinical remission with $43 \%$ of patients requiring the use of immunosuppressants associated with antiviral therapy. ${ }^{2}$ So, this clearly shows that DAAs reduce the need for glucocorticosteroids and immunosuppressants and with higher efficacy. However, we still recommend the use for immunosuppression in patients with severe cryoglobulinemia glomerulonephritis or nervous system disease. Our results demonstrate a rapid virological response and clinical improvement. The HCV viral load dropped dramatically within 4 weeks of treatment, and $83 \%$ of patients had undetectable HCV RNA at week 8, a typical feature found with DAA agents. A rapid clinical improvement of cryoglobulinemia vasculitis symptoms was simultaneously achieved.

We agree with Moiseev et al that long-term follow-up of patients with HCV cryoglobulinemia vasculitis is crucial. In VASCUVALDIC study, one clinical relapse was observed in a patient who was virological relapser. ${ }^{1}$ After long-term follow-up, we observed only one additional relapse in a patient who developed purpura despite a sustained virological response. There was no evidence of $\mathrm{B}$ cell lymphoma. The purpura resolved spontaneously.

DAA offers many other advantages. Their safety profile is much better than previous anti-HCV regimen. Serious adverse events were observed in $8 \%$ of patients treated with sofosbuvir and ribavirin. ${ }^{1}$ By comparison, treatment with peginterferon and ribavirin ${ }^{3}$ and more recently with first-generation protease inhibitors (boceprevir or telaprevir) in combination with peginterferon and ribavirin ${ }^{2}$ had shown very high rates (up to $50 \%$ ) of serious side effects. Interferon $\alpha$ has also well-known potential to exacerbate autoimmune disease states and to induce vasculitis in some patients. ${ }^{4} 5$ DAAs allow a short treatment duration (usually 12 weeks and up to 8 weeks in selected patients), convenience (as few as one pill a day), a very high response rate and a favourable safety profile with few adverse events. Therefore, DAAs (without ribavirin) may increase the tolerance profile and response rates in cryoglobulinemia vasculitis and should be the basis of therapy in these patients.
Whether rituximab will continue to play an important role in the treatment for $\mathrm{HCV}$-associated cryoglobulinemia vasculitis, particularly in severe kidney or nervous system disease is still an open question? Gragnani et $a l^{6}$ have recently reported 44 consecutive patients with $\mathrm{HCV}$-associated cryoglobulinemia vasculitis treated by sofosbuvir-based DAA therapy (individually tailored). All 44 patients were virological responders and 93\% improved clinically. Rituximab was only used in $4.5 \%$ of cases in a recent Italian study. The results from VASCUVALDIC 2 study (NCT02856243) will provide important information regarding this point.

David Saadoun, ${ }^{1,2,3,4,5}$ Patrice Cacoub ${ }^{1,2,3,4,5}$

${ }^{1}$ Sorbonne Universités, UPMC Univ Paris 06, UMR 7211, Paris, France ${ }^{2}$ Inflammation-Immunopathology-Biotherapy Department (DHU i2B), Paris, France ${ }^{3}$ INSERM, UMR_S 959, Paris, France

${ }^{4}$ CNRS, FRE3632, Paris, France

${ }^{5}$ Department of Internal Medicine and Clinical Immunology, AP-HP, Groupe Hospitalier Pitié-Salpêtrière, Paris, France

Correspondence to Dr David Saadoun, Département de Médecine Interne et d'Immunologie clinique, Groupe Hospitalier Pitié-Salpêtrière, 84 Boulevard de I'Hôpital, Paris 75013, France; david.saadoun@aphp.fr

\section{Competing interests None.}

Provenance and peer review Commissioned; internally peer reviewed.

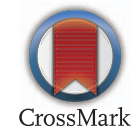

To cite Saadoun D, Cacoub P. Ann Rheum Dis Published Online First: [please include Day Month Year] doi:10.1136/annrheumdis-2016-210695

Received 19 October 2016

Accepted 20 October 2016

\section{Linked}

http://dx.doi.org/10.1136/annrheumdis-2016-210636

Ann Rheum Dis 2016;0:1. doi:10.1136/annrheumdis-2016-210695

\section{REFERENCES}

1 Saadoun D, Thibault V, Si Ahmed SN, et al. Sofosbuvir plus ribavirin for hepatitis C virus-associated cryoglobulinaemia vasculitis: VASCUVALDIC study. Ann Rheum Dis 2016;75:1777-82.

2 Saadoun D, Resche Rigon M, Pol S, et al. PeglFNo/ribavirin/protease inhibitor combination in severe hepatitis $C$ virus-associated mixed cryoglobulinemia vasculitis. J Hepatol 2015;62:24-30

3 Saadoun D, Resche-Rigon M, Thibault V, et al. Antiviral therapy for hepatitis C virus-associated mixed cryoglobulinemia vasculitis: a long-term followup study. Arthritis Rheum 2006;54:3696-706.

4 Gota C, Calabrese L. Induction of clinical autoimmune disease by therapeutic interferon-alpha. Autoimmunity 2003;36:511-8.

5 Boonyapisit K, Katirji B. Severe exacerbation of hepatitis C-associated vasculitic neuropathy following treatment with interferon alpha: a case report and literature review. Muscle Nerve 2002;25:909-13.

6 Gragnani L, Visentini M, Fognani E, et al. Prospective study of guideline-tailored therapy with direct-acting antivirals for hepatitis $C$ virus-associated mixed cryoglobulinemia. Hepatology 2016;64:1473-82. 